\title{
BMJ Open Association between perinatal interventional activity and 2-year outcome of Swiss extremely preterm born infants: a population-based cohort study
}

Mark Adams, ${ }^{1,2}$ Thomas M Berger, ${ }^{3}$ Cristina Borradori-Tolsa, ${ }^{4}$ Myriam Bickle-Graz, ${ }^{5}$ Sebastian Grunt, ${ }^{6}$ Roland Gerull, ${ }^{7}$ Dirk Bassler, ${ }^{1}$ Giancarlo Natalucci, ${ }^{1}$ For the Swiss Neonatal Network \& Follow-Up Group

To cite: Adams M, Berger TM, Borradori-Tolsa C, et al. Association between perinatal interventional activity and 2-year outcome of Swiss extremely preterm born infants: a population-based cohort study. BMJ Open 2019;9:e024560. doi:10.1136/ bmjopen-2018-024560

- Prepublication history and additional material for this paper are available online. To view these files, please visit the journal online (http://dx.doi. org/10.1136/bmjopen-2018024560).

Received 1 June 2018 Revised 5 October 2018 Accepted 11 January 2019
Check for updates

(C) Author(s) (or their employer(s)) 2019. Re-use permitted under CC BY-NC. No commercial re-use. See rights and permissions. Published by BMJ.

For numbered affiliations see end of article.

Correspondence to

Dr Mark Adams;

mark.adams@usz.ch

\section{ABSTRACT}

Objectives To investigate if centre-specific levels of perinatal interventional activity were associated with neonatal and neurodevelopmental outcome at 2 years of age in two separately analysed cohorts of infants: cohort A born at 22-25 and cohort B born at 26-27 gestational weeks, respectively.

Design Geographically defined, retrospective cohort study. Setting All nine level III perinatal centres (neonatal intensive care units and affiliated obstetrical services) in Switzerland.

Patients All live-born infants in Switzerland in 2006-2013 below 28 gestational weeks, excluding infants with major congenital malformation.

Outcome measures Outcomes at 2 years corrected for prematurity were mortality, survival with any major neonatal morbidity and with severe-to-moderate neurodevelopmental impairment (NDI).

Results Cohort A associated birth in a centre with high perinatal activity with low mortality adjusted OR (aOR 0.22; $95 \% \mathrm{Cl} 0.16$ to 0.32 ), while no association was observed with survival with major morbidity (aOR $0.74 ; 95 \% \mathrm{Cl} 0.46$ to 1.19 ) and with NDI (aOR $0.97 ; 95 \% \mathrm{Cl} 0.46$ to 2.02 ). Median age at death (8 vs 4 days) and length of stay (100 vs 73 days) were higher in high than in low activity centres. The results for cohort B mirrored those for cohort A.

Conclusions Centres with high perinatal activity in Switzerland have a significantly lower risk for mortality while having comparable outcomes among survivors. This confirms the results of other studies but in a geographically defined area applying a more restrictive approach to initiation of perinatal intensive care than previous studies. The study adds that infants up to 28 weeks benefited from a higher perinatal activity and why further research is required to better estimate the added burden on children who ultimately do not survive.

\section{INTRODUCTION}

Over recent decades, progress in perinatal care has led to vastly improved survival rates
Strengths and limitations of this study

- Geographically defined cohort study comparing 2-year outcome of extremely preterm infants between hospitals with high and low perinatal interventional activity based on a quantitative score of 3 obstetric and 4 neonatal indicators.

- Crude and risk-adjusted ORs for outcome between high and low activity centres were calculated using regression models and measuring predictive validity of risk adjustment.

- Missing outcome data of surviving infants lost to follow-up were addressed by multiple imputation and the validity of data imputation was tested by sensitivity analysis using non-imputed data.

- The inter-relatedness of some of the perinatal activity score components (eg, surfactant and respiratory support) form a limitation. However, our aim was to quantify activity and not measure quality of care. As such, the components quantify at best the level of proactive care by focusing on the whole repertoire of first perinatal supportive interventions.

- Further minor limitations are represented by the composite nature of the outcome measures 'any major morbidity' and 'neurodevelopmental impairment', which could have led to a loss of information.

for infants born at extremely low gestational age (GA). Consequently, the GA limit for initiating life-sustaining intensive care at birth was lowered to 22 weeks, below which treatment is generally not recommended. ${ }^{1}$ This, however, raised ethical concerns regarding the added burden to infants who ultimately do not survive and the increased risk of neurosensory impairment among those that do survive. ${ }^{2}$ There is little consensus about the policy of treating these infants. Instead, hospital practices regarding the initiation of intensive care have dramatically influenced 
rates of survival and survival without impairment. ${ }^{3}$ This has led to large outcome variation among hospitals. In 2015, Rysavy et al quantified the effect of perinatal interventional activity on outcome between a group of 24 centres of the Eunice Kennedy Shriver National Institute of Child Health and Human Development (NICHD) network in the USA. Among infants born at 22-23 weeks gestation, centre rates of active treatment accounted for $78 \%$ of the variation in survival between centres. For those born at 24 weeks gestation, it accounted for $22 \%$ of the variation. ${ }^{4}$ There is a similar variation in decision-making approaches in Europe, which appears to reflect local philosophy and practice rather than economic or demographic markers, individual variations in health expenditure or rates of preterm birth. ${ }^{5}$

Swiss obstetricians and neonatologists are known to be generally restrictive with regard to initiation of intensive care for infants at the limit of viability. A recent study revealed that the decision-making regarding initiation of treatment was based almost exclusively on GA and that most infants born $<24$ weeks gestation received a priori comfort care. ${ }^{6}$ Nevertheless, centre-to-centre outcome variability has repeatedly been reported and is assumed to be in part associated with the local ethical decision-making. ${ }^{7-9}$ What remained unclear was whether the lower mortality in some centres leads to higher risk of neurodevelopmental impairment (NDI) in survivors.

This study aimed to quantify the outcome differences between centres with a higher propensity towards providing active perinatal care at birth from those that provide more a priori comfort care. We assessed infants in cohort A ( $22+0$ to $25+6$ weeks GA) and compared their outcome variability with that in cohort B $(26+0$ to $27+6$ weeks GA) where we expected no difference in either perinatal care provision or outcome based on previous studies. $^{40-13}$

\section{METHODS}

\section{Study population and procedure}

Geographically defined, retrospective cohort study including all live-born infants between $22+0$ and $27+6$ weeks of gestation in Switzerland from 2006 to 2013. We excluded infants born with a major congenital malformation, defined as being the primary cause of death or requiring surgery or a chromosomal anomaly. We also excluded four infants born and treated exclusively in three step-down units. We extracted electronically recorded data (challenged for plausibility and completeness) from the prospective national database of the Swiss Neonatal Network \& Follow-up Group (SNN). Data from delivery room deaths were audited by a researcher visiting the hospitals' maternity wards.

Participating centres were obliged to inform parents about the scientific use of anonymised data.

\section{Neonatal data}

Perinatal and neonatal variables were defined as follows: GA as the best estimate available based on prenatal ultrasound examination during the first trimester of pregnancy. Birthweight z-scores, intraventricular haemorrhage grade 3 or higher (IVH), cystic periventricular leukomalacia (cPVL), bronchopulmonary dysplasia (BPD), severe retinopathy of prematurity stages 3-4 (ROP), necrotising enterocolitis (NEC), late-onset neonatal sepsis (LOS) and socioeconomic status (SES) were defined as previously published. ${ }^{14}$

\section{Neurodevelopmental outcome at 2 years of age}

Experienced neurodevelopmental or developmental paediatricians performed the standardised Swiss follow-up assessment ${ }^{15}$ at 18-24 months corrected age in one of the Swiss follow-up centres. Between 2006 and 2012, examinations were based on Bayley Scales of Infant Development, 2 edition (BSID-II) ${ }^{16}$ and afterwards on Bayley Scales of Infant and Toddler Development, 3 edition (Bayley-III). ${ }^{17}$ Up until 2006, some of the children were tested using the Griffiths Mental Development Scales-Revised (GMDS) ${ }^{18}$ during the transition period to BSID-II. According to recent literature, ${ }^{19-22}$ Bayley-III scores below 85 (-1SD) were considered as equivalent of indices below 70 (-2SD) in the BSID-II and the GMDS. The GMDS development quotient was considered equivalent to BSID-II Mental Developmental Index. ${ }^{23}$ Infants with significant disability precluding completion of the development test were assigned a development score of 1 below -3SD. Cerebral palsy was defined according to Rosenbaum $e t a l^{44}$ and was graded according to the Gross Motor Function Classification System (GMFCS) for children aged $\leq 2$ years. ${ }^{25}$ Vision and hearing were assessed by either direct examination or caregiver report.

\section{Perinatal interventional activity score}

In order to differentiate between Swiss centres with a higher propensity to initiate intensive care for infants born below 26 weeks gestation, we calculated a perinatal activity score per centre based on the model presented by Serenius et al. ${ }^{10}$ Obstetric and neonatal activity scores reflecting the intensity of care in each centre were calculated on the basis of the rates of three key obstetric indicators (delivery at level III hospitals, that is, inborn; complete course of antenatal steroids; caesarean section), and four key neonatal indicators (surfactant within 2 hours after birth; any of the following activities in the delivery room: bag/mask ventilation, continuous positive airway pressure, endotracheal intubation, epinephrine or epinephrine supply, cardiac compression; no recorded decision for primary non-intervention in the delivery room (available for all infants); infants admitted for intensive care (out of infants alive at $30 \mathrm{~min}$ after birth)). The mean obstetric and neonatal activity scores comprised the perinatal activity score (henceforth, activity score). Each step included normalisation by assigning the centre with the highest rate for each indicator a score of 100 ; 
the remaining centres were assigned proportional scores. We calculated an activity score for infants born between 22-25 weeks gestation (cohort A) and a separate one for infants born 26-27 weeks gestation (cohort B). The first score was used to classify the nine Swiss perinatal centres into a 'low' and a 'high' activity group using the arbitrary threshold of an activity score of 80 in order to generate two groups of similar size with clear difference in perinatal activity. To allow comparison between cohort A and cohort B, cohort B was split into the same centres with low and high activity as for cohort A. To confirm the dichotomous association of perinatal activity with outcome, we also tested for a linear association. For this, we generated a variable that increases by one for every 5-point increase in perinatal activity using the two perinatal activity scores for cohort A and B.

\section{Outcome}

Outcome parameters were defined as follows: mortality at 2 years corrected age, death or moderate-to-severe NDI, death or major morbidity, survival with moderate-to-severe NDI and survival with major morbidity. Moderate-to-severe NDI was defined as either mental or motor development index below 70 (-2SD) in the BSID-II; cognitive or motor composite score below 85 (see below) in the Bayley-III; a global score of the GMDS below 70 (-2SD); cerebral palsy with GMFCS above 1; the absence of useful hearing even with aids (ie, $>90 \mathrm{~dB}$ hearing level); blindness or only perception of light. Major morbidities encompassed IVH, cPVL, BPD, ROP, NEC or LOS.

\section{Data completeness}

Patient population coverage was assessed by comparison with the birth registry of the Swiss Federal Statistical Office and yielded $86.4 \%$ of all live births between 22 and 27 weeks gestation. $1.2 \%$ of the datasets were missing information on 'major morbidity' and were therefore eliminated in the non-imputed analyses including this outcome. Other data were missing in less than $0.1 \%$ of cases. As 2-year follow-up data were missing in $11 \%$ of all surviving infants between 22 and 25 weeks gestation and $17 \%$ between of 26 and 27 weeks gestation, we performed a fivefold imputation with chained equations for the cohorts A (all infants), A (survivors), B (all infants) and B (survivors), respectively, allowing the calculation of pooled adjusted ORs (aORs) for the above-listed outcomes. ${ }^{26}$ Data for imputation were determined as missing at random. As a sensitivity analysis, we performed the same tests with crude, that is, non-imputed data. As outborn infants were by concept unevenly distributed between high and low activity centres, they cannot be assumed to be missing at random for the imputation. We, therefore, performed another sensitivity analysis excluding all outborn infants for both the activity score as well as for the regression analysis.

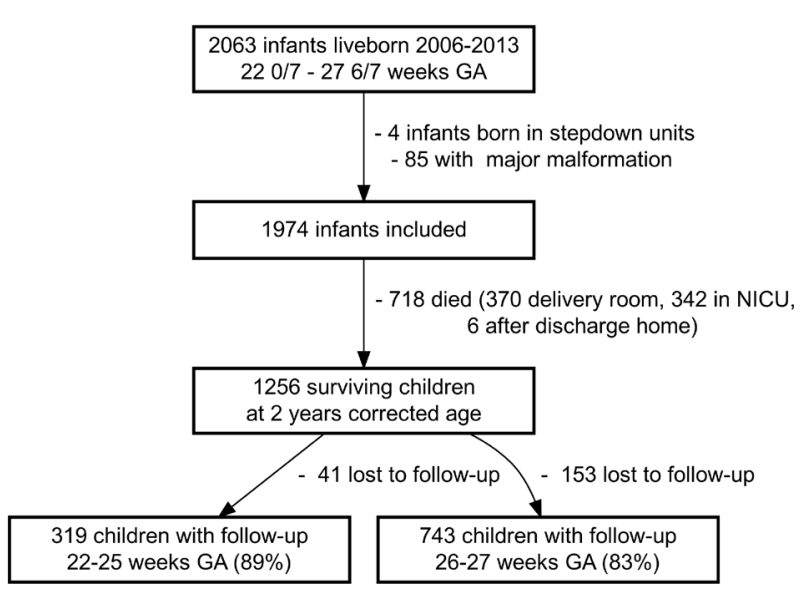

Figure 1 Study population overview. GA, gestational age; $\mathrm{NICU}$, neonatal intensive care unit.

\section{Statistical analysis}

We performed multivariable-adjusted logistic regression to compare outcome between centres with lower and higher perinatal activity. Adjustment was made for GA and $\mathrm{GA}^{2}$ (as the combination better models the non-linear dependency of most neonatal outcomes on GA and therefore results in risk adjustment with higher predictive validity), birthweight z-score, male sex, multiple births and SES. To estimate the validity of the adjustment, we calculated how well the above listed variables predicted outcome. If this predicted validity is low, the adjustment made has limited explanatory power. ${ }^{27} \mathrm{We}$ calculated the area under receiver operating characteristics curve (AUC). AUC values between 0.7 and 0.8 were considered to represent moderate, and $>0.8$ to represent high predictive validity, respectively. All statistical analyses were performed using R V.3.4. ${ }^{28}$

\section{RESULTS}

\section{Study population and neonatal data}

A total of 2063 infants were born alive in Switzerland between 2006 and 2013 below 28 weeks gestation (figure 1). A total of 1839 of those infants were registered by SNN between 2007 and 2013. They correspond to 1900 life births registered at the Swiss Federal Statistical Office in the same time period which results in a population coverage of $97 \%$ for the study period (reference data for 2006 were not available as GA was not included in the national register prior to 2007). Of the 2063 infants, we excluded four infants because they were born in and treated at three step-down units and 85 infants because of major congenital malformations. Among the 1974 included infants, $712(36 \%)$ died before discharge and $6(0.3 \%)$ after discharge but before reaching 2 years of age. In cohorts A and B, 319 (89\% of survivors) and 743 $(83 \%)$ were assessed at 2 years corrected age, respectively. One hundred ninety-four $(15 \%)$ children were lost to follow-up (109 refused follow-up, 57 could not be reached/moved away, 28 unknown loss to follow-up). In 
Table 1 Baseline characteristics cohorts A/B: children with and without 2-year follow-up (FU)

\begin{tabular}{llllll} 
& \multicolumn{2}{l}{ Cohort A (22-25 weeks GA) } & & \multicolumn{2}{l}{ Cohort B (26-27 weeks GA) } \\
\cline { 2 - 3 } \cline { 5 - 6 } & With FU & Lost to FU & & With FU & Lost to FU \\
\hline N & $319(88.6 \%)$ & $41(11.4 \%)$ & & $743(82.9 \%)$ & $153(17.1 \%)$ \\
GA (IQR) & $25.3(24.7-25.6)$ & $25(24.6-25.6)$ & $27(26.4-27.4)$ & $27(26.6-27.4)$ \\
BW z-score (IQR) & $-0.1(-0.6$ to 0.4$)$ & $-0.3(-0.6$ to 0.3$)$ & $0(-0.7$ to 0.5$)$ & $0.2(-0.5$ to 0.5$)$ \\
Male sex & $53.9 \%$ & $48.8 \%$ & $52.9 \%$ & $56.2 \%$ \\
Multiple births & $22.3 \%$ & $26.8 \%$ & $26.8 \%$ & $24.8 \%$ \\
Outborn & $2.2 \%$ & $9.8 \%$ & $4.2 \%$ & $7.2 \%$ \\
SES (IQR) & $6(5$ to 8$)$ & $7(4.2$ to 10$)$ & $6(4$ to 8$)$ & $6(4$ to 8$)$ \\
Activity score (IQR) & $87.5(73.7-89.2)$ & $84.1(77.8-89.2)$ & $85.8(84.2-91)$ & $88.7(84.2-91)$ \\
\hline Major morbidity & $60.8 \%$ & $53.7 \%$ & $39.9 \%$ & $35 \%$ \\
\hline
\end{tabular}

SES, socioeconomic status was calculated by means of a score reflecting both maternal education and paternal occupation, with a maximum and minimum scores of 12 and 2, indicating lower and higher status, respectively.

BW, birth weight; GA, gestational age.

both cohorts, difference between baseline characteristics of children with and without follow-up was negligible (table 1), particularly concerning the factor 'activity score' which determines the comparison groups for the subsequent analysis. Outborn children were less frequently assessed in both cohorts.

\section{Perinatal interventional activity score}

Table 2 displays the proportion of infants receiving either of the treatments determining the obstetrical activity $\left(\right.$ items ${ }^{1-3}$ ) and the neonatal activity (items ${ }^{4-7}$ ) for cohort A in each centre. Activity scores were determined out of the mean of the obstetric and neonatal activity scores and ranged from 57 to 98 . Four centres with an activity score $<80$ were classified as 'low activity centres' encompassing 461 infants in cohort A and 554 in cohort B. The remaining five centres were classified as 'high activity centres' and combined 466 infants in cohort A and 493 in cohort B. A separate centre-specific activity score was determined for cohort B using the same routine (online supplementary table 1). Each 5-point increase in perinatal activity score reduced the risk for mortality within 2 years of life for cohort A (aOR $0.74,95 \%$ CI 0.68 to 0.80 ) and cohort B (aOR $0.82,95 \%$ CI 0.70 to 0.97 ).

After risk adjustment, the aOR in cohort A for mortality $(0.22,95 \%$ CI 0.15 to 0.31$)$ and death or NDI (0.30, $95 \%$ CI 0.21 to 0.42 ) were significantly lower (figure 2 ) for high compared with low activity centres. After restricting the cohort to survivors, aOR for any major neonatal morbidities was 0.75 (95\% CI 0.47 to 1.19$)$ and for moderate-to-severe NDI 0.95 (95\% CI 0.46 to 1.98). The crude baseline characteristics of low versus high activity centres in cohort A (table 3) were comparable

Table 2 Centre activity grouping cohort A (standardised ratios)

\begin{tabular}{lcccccccccc} 
& C 1 & C 2 & C 3 & C 4 & C 5 & C 6 & C 7 & C 8 & C 9 & $\begin{array}{l}\text { Highest } \\
\text { proportion* }\end{array}$ \\
\hline Inborn (1) & 95 & 98 & 94 & 96 & 96 & 99 & 100 & 96 & 97 & $100 \%$ \\
Full course antenatal steroids (2) & 56 & 64 & 80 & 88 & 91 & 81 & 100 & 88 & 97 & $51.5 \%$ \\
Caesarean section (3) & 44 & 81 & 67 & 50 & 88 & 100 & 93 & 97 & 93 & $60.7 \%$ \\
Obstetric activity & 66 & 83 & 82 & 80 & 94 & 96 & 100 & 96 & 98 & - \\
Delivery room intubation or CPAP (4) & 37 & 40 & 61 & 83 & 76 & 83 & 83 & 93 & 100 & $71.9 \%$ \\
Surfactant <2 hours (5) & 44 & 39 & 51 & 35 & 73 & 82 & 84 & 97 & 100 & $65.6 \%$ \\
Intensive care started (6) & 57 & 78 & 78 & 100 & 79 & 83 & 81 & 88 & 99 & $81.7 \%$ \\
Admitted (7) & 57 & 64 & 77 & 92 & 79 & 79 & 76 & 88 & 100 & $81.2 \%$ \\
Neonatal activity & 49 & 55 & 67 & 78 & 77 & 82 & 81 & 92 & 100 & - \\
Activity score & 57 & 68 & 74 & 78 & 84 & 88 & 89 & 93 & 98 & - \\
Activity group & Low & Low & Low & Low & High & High & High & High & High & - \\
\hline
\end{tabular}

(1)-3): key obstetric indicators; (4)-(7): key neonatal indicators; C1-C9: centres 1-9.

${ }^{*}$ Highest proportion: actual proportion of infants receiving intervention in centre with highest incidence, standardised as 100 in activity score.

CPAP, continuous pulmonary airway pressure. 

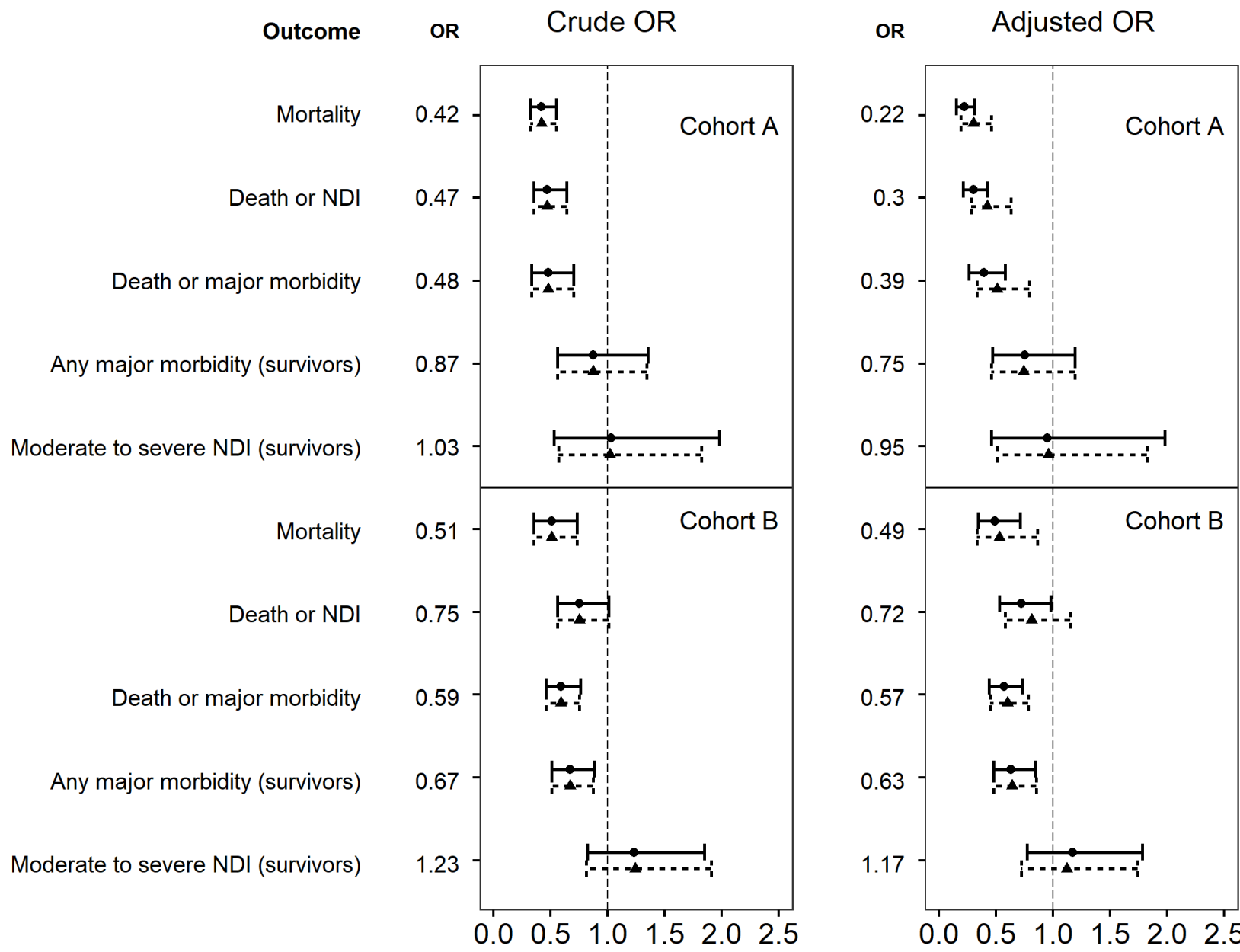

AUC

Figure 2 ORs of outcome when born in a unit with high perinatal interventional activity. ORs with $95 \% \mathrm{Cl}$ of outcome when born in high activity units, crude or adjusted for GA, GA ${ }^{2}$, birthweight z-score, male sex, multiple births and socioeconomic status. Dotted lines represent results received when using non-imputed data. AUC, area under receiver operator characteristic curve representing predictive validity of risk adjustment. GA, gestational age; NDI, neurodevelopmental impairment.

for size, GA range, birthweight z-score, multiple births and SES. However, high activity centres had more male infants and less outborn infants. The crude outcome proportions reflect the aOR results. Repeating the same evaluation using non-imputed data resulted in almost the same point estimates and CIs (dotted lines in figure 2). As outborn infants were unevenly distributed between children with and without follow-up, we repeated the analysis excluding all 75 outborn infants from the beginning for both the activity score and the regression analysis. The resulting aOR was almost equivalent to the ones reported above (online supplementary figure 1). Excluding the delivery room deaths, median neonatal intensive care unit (NICU) age at death in high activity centres was higher ( 8 vs 4 days) as was length of stay (100 vs 73 days). As can be seen in figure 3 , the distribution of age at death was different between high and low activity centres. In high activity centres, the highest density was reached above the median, whereas it was below the median in low activity centres. The violin plot thereby allows taking the full distribution of the data into account rather than relying on median and IQR alone.

Centres classified as having 'high activity' for cohort A, still had a higher perinatal activity score (91 vs 84) in cohort B with matching outcome variability. aOR for mortality $(0.49,95 \%$ CI 0.34 to 0.71$)$ and death or NDI $(0.72,95 \%$ CI 0.53 to 0.97$)$ were significantly lower in high activity centres (figure 2). In contrast to cohort A, the aOR for any major morbidities was also significantly lower $(0.63,95 \%$ CI 0.48 to 0.84$)$ whereas moderate-to-severe NDI outcome in survivors was higher without reaching significance $(1.17,95 \% \mathrm{CI} 0.77$ to 1.78$)$. Again, crude baseline characteristics (table 3) were comparable with more male and fewer outborn infants in high activity centres. Crude outcomes mirror the aOR result. In cohort $\mathrm{B}$, median age at death in NICU in high activity centres was again higher (11 vs 6 days), whereas length of stay was only somewhat longer ( 85 vs 78 days). 
Table 3 Low versus high activity centres cohorts $A$ and $B$

\begin{tabular}{|c|c|c|c|c|}
\hline & \multicolumn{2}{|c|}{ Cohort A (22-25 weeks GA) } & \multicolumn{2}{|c|}{ Cohort B (26-27 weeks GA) } \\
\hline & Low activity & High activity & Low activity & High activity \\
\hline $\mathrm{N}$ & $461(49.7 \%)$ & 466 (50.3\%) & 554 (52.9\%) & $493(47.1 \%)$ \\
\hline $\begin{array}{l}\text { GA } \\
(I Q R)\end{array}$ & 24.7 (24-25.3) & $24.6(23.6-25.3)$ & $26.9(26.4-27.4)$ & 27 (26.4-27.4) \\
\hline $\begin{array}{l}\text { BW z-score } \\
\text { (IQR) }\end{array}$ & $-0.3(-0.8$ to 0.3$)$ & $-0.4(-1$ to 0.2$)$ & $0(-0.7$ to 0.5$)$ & $0(-0.8$ to 0.5$)$ \\
\hline Male sex & $51.6 \%$ & $57.6 \%$ & $52.1 \%$ & $55.8 \%$ \\
\hline Multiple births & $28.2 \%$ & $27.5 \%$ & $24.2 \%$ & $28.2 \%$ \\
\hline Outborn & $3.9 \%$ & $2.1 \%$ & $5.2 \%$ & $3.4 \%$ \\
\hline SES (IQR) & $6(4-8)$ & $6(5-8)$ & $6(4-8)$ & $6(4-8)$ \\
\hline $\begin{array}{l}\text { Activity score } \\
\text { (IQR) }\end{array}$ & $68.1(68.1-73.7)$ & $89.2(87.5-92.7)$ & $84.2(83.3-85.8)$ & $91(90.2-92.3)$ \\
\hline Mortality & $71.4 \%$ & $51.1 \%$ & $18.2 \%$ & $10.1 \%$ \\
\hline Died in delivery room & $41.9 \%$ & $34.1 \%$ & $1.6 \%$ & $1.8 \%$ \\
\hline NICU mortality & $29.5 \%$ & $17 \%$ & $16.6 \%$ & $8.3 \%$ \\
\hline Death or NDI & $78.2 \%$ & $62.9 \%$ & $30.3 \%$ & $24.6 \%$ \\
\hline Any major morbidity (survivors) & $62.1 \%$ & $58.7 \%$ & $43.8 \%$ & $34.2 \%$ \\
\hline Moderate-to-severe NDI (survivors) & $18.3 \%$ & $18.6 \%$ & $11.9 \%$ & $14.3 \%$ \\
\hline Age at death in NICU (days) (IQR) & $4(1.5-10.2)$ & $8(1.5-18)$ & $6(3-14)$ & $13(4-24)$ \\
\hline Length of stay (days) (IQR) & $73.5(4-101.8)$ & $100(63-120)$ & 79 (64-95) & $85(72-97)$ \\
\hline
\end{tabular}

SES, socioeconomic status was calculated by means of a score reflecting both maternal education and paternal occupation, with a maximum and minimum scores of 12 and 2, indicating lower and higher status, respectively.

BW, birth weight; GA, gestational age; NDI, neurodevelopmental impairment; NICU, neonatal intensive care unit.

Cohort A (22 - 25w GA)

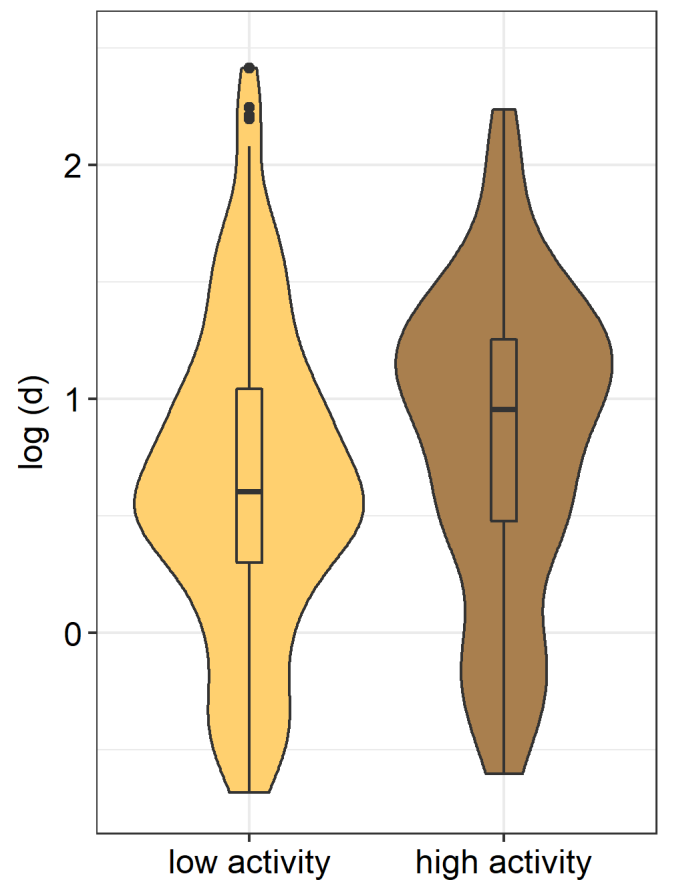

Cohort B (26 - 27w GA)

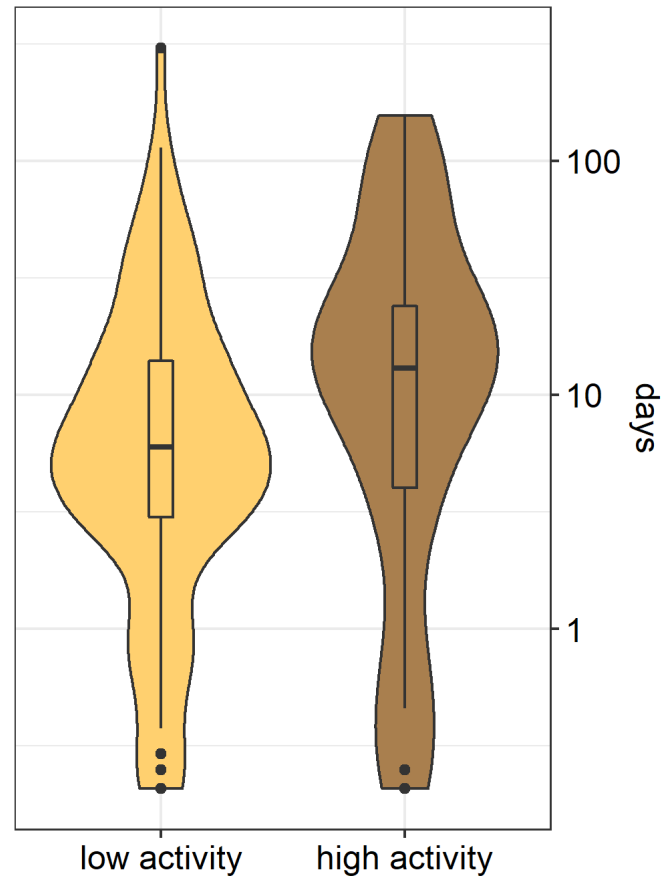

Figure 3 Age at death in NICU (days). Log-transformed age at death in NICU (days) for low and high activity centres in cohort A and cohort B. Crude y-axis scale on right-hand side. Violin plot: box-plot with median, IQR and density (width=frequency). GA, gestational age; NICU, neonatal intensive care unit. 
Table 4 Outcome at 2 years of age (corrected)

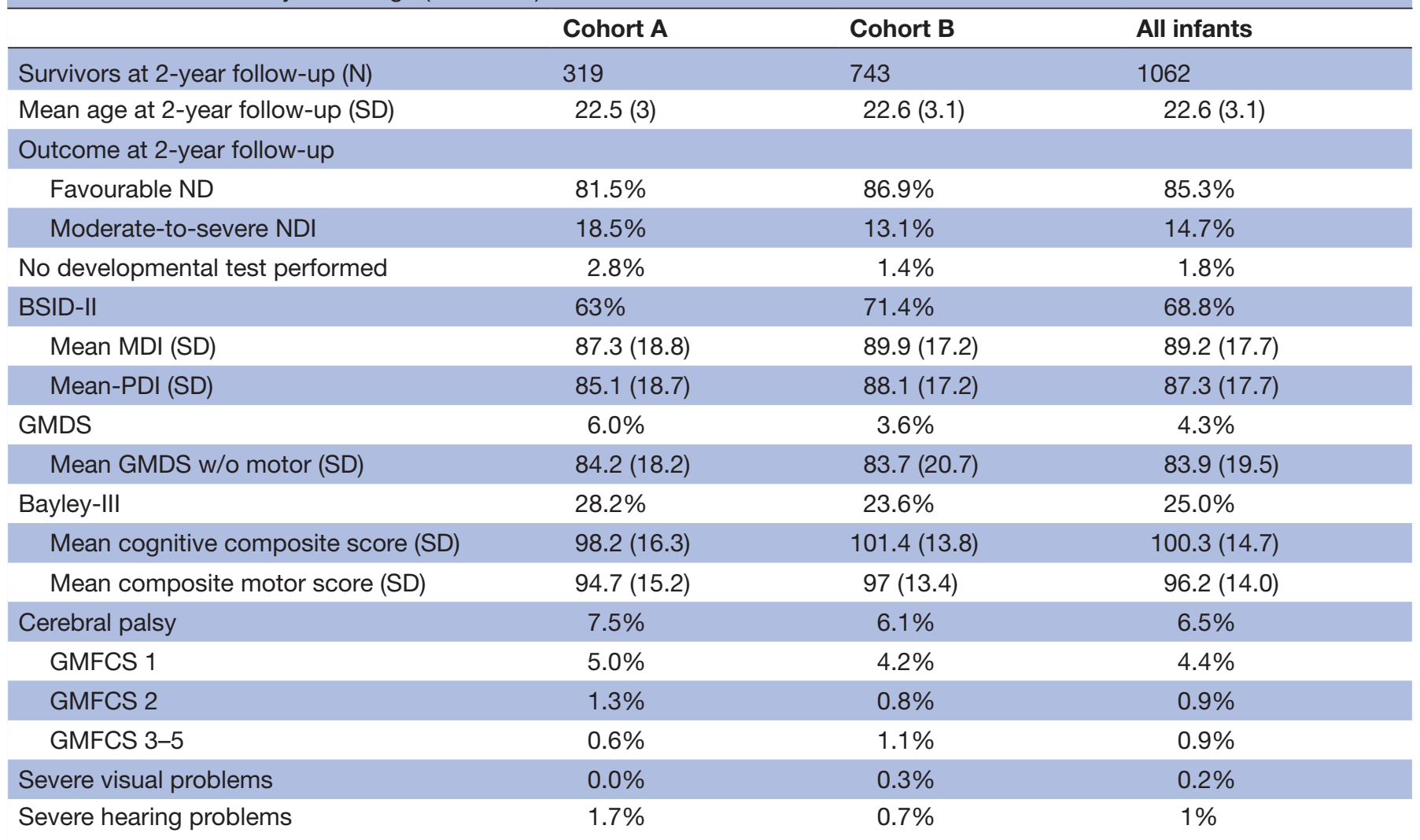

Cohort B: 26 0/7 to 27 6/7 weeks gestation; Cohort A: 22 0/7 to 25 6/7 weeks gestation.

BSID-II, Bayley Scales of Infant Development, second edition; BSID-III/B-III, Bayley Scales of Infant and Toddler Development, third edition; Favourable ND, favourable neurodevelopment, that is, absence of any NDI; GMDS, Griffiths Mental Developmental Scales; GMFCS, Gross Motor Function Classification System; MDI, Mental Developmental Index; NDI, neurodevelopmental impairment; PDI, Psychomotor Developmental Index.

\section{Neurodevelopmental outcome at 2 years of age}

Follow-up assessment was performed at a mean (SD) corrected age of 22.6 (3.1) months (table 4). Of 1062 examined children, $729(69 \%), 265(25 \%)$ and $46(4 \%)$ were assessed with the Bayley-II, Bayley-III and GMDS, respectively, while in $19(2 \%)$ children only a part of a developmental assessment could be performed because of severe cerebral palsy or poor compliance. A total of 220 $(21 \%)$ infants suffered from moderate-to-severe NDI and $842(79 \%)$ infants showed favourable outcome.

\section{DISCUSSION}

Swiss perinatal centres with a higher score of perinatal activity for infants at the borderline of viability (cohort A) had significantly lower aOR for mortality and for the composite outcome death or NDI. After restricting the cohort to survivors at 2 years of age corrected for prematurity, there was no significant difference between centres with high and low intensity regarding risk for major morbidity or NDI. Cohort B mirrored the outcome differences between high and low activity perinatal centres determined for cohort A, that is, significantly lower aOR for mortality and for death or NDI. In contrast to cohort A, the lower mortality in high activity centres in cohort B was based exclusively on NICU mortality. High activity centres in cohort B had a significantly lower aOR for any major neonatal morbidity. Except for the aOR for mortality, death or NDI or any major morbidity in cohort A, the predictive validity measured by AUC was low to negligible. For those aORs, we would expect the true value to lie between the crude and the adjusted level, which confirm the results. ${ }^{29}$

The association between perinatal interventional activity and outcome has been reported before. We based our centre-specific activity score on the model of the Swedish regional activity score published by Serenius $e t$ $a l .{ }^{10}$ In their study, live-born infants between 22 and 24 weeks GA treated in regions with high versus low activity also had lower aOR for mortality $(0.43,95 \%$ CI 0.26 to 0.73 ) and for death or NDI (aOR $0.48,95 \%$ CI 0.27 to 0.84 ) at 2.5 years corrected age. As in our study, survivors in high activity regions did not have a higher risk for any NDI (aOR $0.63,95 \%$ CI 0.31 to 1.28$)$. This reflects the difficulty in assessing outcome at 2 years in general and using NDI as a measure of efficacy. ${ }^{30}$ Other reports between intensity of care and survival date back as far as 2004 when Håkansson et al for the first time reported how a proactive perinatal strategy increases the number of 
live births and improves the infant's postnatal condition in Sweden. ${ }^{32}$ Rysavy et al were also able to show a clear association between the outcome of infants receiving active care and those that did not for infants between 22 and 24 weeks GA, but not for those between 25 and 26 weeks GA. ${ }^{4}$ A study determining the perinatal outcome for extremely preterm infants in relation to place of birth in England reported lower odds for mortality when they were born in a level 3 centre with higher perinatal activity based on staffing and activity data collected by questionnaire. ${ }^{11}$ In 2013, an NICHD study could show that "centre intervention rates' significantly predicted mortality rates for infants $<25$ weeks but not for infants $\geq 25$ weeks gestation. ${ }^{12}$ Centre intervention rates included parameters similar or identical to the ones chosen for the calculation of the activity score in this study. Using yet another version of a similar intervention score, the MOSAIC study of 2009 (Models of OrganiSing Access to Intensive Care for very preterm births) was able to show an association between the score and mortality for infants $<26$ weeks but not for infants at 26-27 weeks gestation. ${ }^{13}$ Swiss centres rarely initiated intensive care below 24 weeks gestation during the study period. ${ }^{6}{ }^{8}$ This is why we chose the same GA ranges for cohorts A and B as the MOSAIC study but not as the other studies. Yet, even with the more restrictive approach, we confirm the results of previous studies in infants $<26$ weeks gestation.

Swiss centres classified as having 'high activity' for cohort A still had a higher perinatal activity score in cohort B. In contrast to the studies reported above, ${ }^{40-13}$ the resulting outcome variability in cohort $B$ is congruent to the variability in cohort $\mathrm{A}$. As variability in mortality in cohort B was exclusively observed in NICU but not in delivery room-mortality, it is difficult to determine an association to either higher perinatal activity or quality of care, or a combination of both. Arguments exist for each: centres of the high activity group also have a higher perinatal activity score in cohort B and the continuous perinatal activity score reduces risk of mortality per each 5-point increase in activity score. As variability in mortality in cohort B exists exclusively for NICU and not for delivery room mortality, variability in the decision-making process regarding redirection of care based on futility may exist. On the other hand, centres with a high perinatal activity also had a significantly lower aOR for any major morbidities which would favour the assumption of difference in quality of care. This would be in line with the observations by Smith et al whose findings suggest that the approach taken with infants at the limits of viability is associated with improved outcomes of more-mature infants. ${ }^{33}$

As reported in other studies, ${ }^{10}{ }^{34}$ median age at death was higher in high activity centres. Serenius $e t$ al argue that the longer duration of life allows for a trial of life, whereas Costeloe $e t$ alsee the reason in different principle causes of death with a tendency towards later complications of prematurity in the case of the group of infants dying later. ${ }^{1034}$ Figure 3 displays that the age at death for both cohorts are comparable in their IQR but, together with the longer median length of stay for all infants, indicate an added burden to infants who ultimately do not survive in high activity centres.

\section{CONCLUSIONS}

A 5-point increase in perinatal interventional activity significantly decreases the aOR for mortality of infants born 22-25 weeks gestation in Switzerland. High activity centres have a significantly lower aOR for mortality and death or NDI and outcome among survivors at 2 years of age is comparable. The effect observed was repeated for infants between 26 and 27 weeks gestation, indicating that all extremely preterm infants benefited. Age at death and duration of hospitalisation are higher suggesting a higher burden for patients who ultimately do not survive in high activity centres. Although the results favour the high activity approach, further research is required to better estimate the accompanying added burden on the children. Outcome data at 5 years of age or later are urgently required to confirm these findings with a more predictive long-term assessment.

\section{Author affiliations}

${ }^{1}$ Department of Neonatology, Universitätsspital Zürich, Zürich, Switzerland ${ }^{2}$ Epidemiology, Biostatistics and Prevention Institute, University Zürich, Zürich, Schweiz, Switzerland

${ }^{3}$ Neonatal and Paediatric Intensive Care Unit, Kinderspital Luzern, Luzern, Switzerland

${ }^{4}$ Department of Paediatrics, Geneva University Hospital, Geneva, Switzerland ${ }^{5}$ Department Woman-Mother-Child, University Hospital Lausanne, Lausanne, Switzerland

${ }^{6}$ Division of Neuropaediatrics, Development and Rehabilitation, Children's University Hospital, Inselspital, University of Bern, Bern, Switzerland

${ }^{7}$ Department of Neonatology, University of Basel Children's Hospital (UKBB), Basel, Switzerland

Acknowledgements We gratefully thank all children and their parents who participated in this study. We also thank the following members of the Swiss Neonatal Network \& Follow-Up Group.

Collaborators Swiss Neonatal Network \& Follow-up Group: Aarau: Cantonal Hospital Aarau, Children's Clinic, Department of Neonatology (Ph. Meyer, C. Anderegg), Department of Neuropaediatrics (A. Capone Mori, D. Kaeppeli); Basel: University of Basel Children's Hospital (UKBB), Department of Neonatology (S. Schulzke), Department of Neuropaediatrics and Developmental Medicine (P. Weber); Bellinzona: San Giovanni Hospital, Department of Paediatrics (G.P. Ramelli, B. Goeggel Simonetti); Berne: University Hospital Berne, Department of Neonatology (M. Nelle), Department of Paediatrics (B. Wagner), Department of Neuropaediatrics (M. Steinlin, S. Grunt); Biel: Children's Hospital Wildermeth, Department of Pediatrics (M. Gebauer), Development and Paediatric Neurorehabilitation Center (R. Hassink); Chur: Children's Hospital Chur, Department of Neonatology (W. Bär), Department of Neuropaediatrics (E. Keller, Ch. Killer); Fribourg: Cantonal Hospital Fribourg, Department of Neuropaediatrics (K. Fuhrer); Geneva: Department of child and adolescent, University Hospital (HUG), Neonatology Units (R. E. Pfister), Division of Development and Growth (P. S. Hüppi, C. Borradori-Tolsa); Lausanne: University Hospital (CHUV), Department of Neonatology (J.-F. Tolsa, M. Roth-Kleiner), Department of Child Development (M. Bickle-Graz); Lucerne: Children's Hospital of Lucerne, Neonatal and Paediatric Intensive Care Unit (T. M. Berger), Department of Neuropaediatrics (T. Schmitt-Mechelke, F. Bauder); Lugano: Regional Hospital Lugano, Department of Paediatrics (V. Pezzoli); Muensterlingen: Cantonal Hospital Muensterlingen, Department of Paediatrics (B. Erkert, A. Mueller); Neuchatel: Cantonal Hospital Neuchatel, Department of Paediatrics (M. Ecoffey); St. Gallen: Cantonal Hospital St. Gallen, Department of Neonatology (A. Malzacher), Children's Hospital St. Gallen, Neonatal and Paediatric Intensive Care Unit (J. P. Micallef), Department of Child Development (A. Lang-Dullenkopf); Winterthur: Cantonal 
Hospital Winterthur, Department of Neonatology (L. Hegi), Social Paediatrics Center (M. von Rhein); Zurich: University Hospital Zurich (USZ), Department of Neonatology (D. Bassler, R. Arlettaz), University Children's Hospital Zurich, Department of Neonatology (V. Bernet) and Child Development Center (B. Latal, G. Natalucci); Zollikerberg: Hospital Zollikerberg, Neonatology Clinic (M. Moenkhoff).

Contributors MA performed the biostatistical evaluation and together with GN was involved in study design, data collection, analysis and interpretation of the results and wrote, reviewed and revised the manuscript. TMB, DB, CB-T, MB-G, SG and $R G$ were involved in data collection, study design, analysis and interpretation of data and reviewed the manuscript. All authors approved the final manuscript as submitted and agree to be accountable for all aspects of the work

Funding MA receives a salary as network coordinator for the Swiss Neonatal Network. GN received financial support by the Swiss National Science Foundation; grant PZ00P3_161146.

Disclaimer The authors received no specific funding for this work. The sponsors were not involved in the following matters: study design; collection, analysis, and interpretation of data; writing of the report and the decision to submit the manuscript for publication.

Competing interests MA receives a salary as network coordinator for the Swiss Neonatal Network.

Patient consent for publication Not required.

Ethics approval Data collection and evaluation for this study has been approved by the institutional ethical review board (KEK-ZH-Nr 2014-0552).

Provenance and peer review Not commissioned; externally peer reviewed.

Data sharing statement Additional data are available by emailing mark.adams@ usz.ch.

Open access This is an open access article distributed in accordance with the Creative Commons Attribution Non Commercial (CC BY-NC 4.0) license, which permits others to distribute, remix, adapt, build upon this work non-commercially, and license their derivative works on different terms, provided the original work is properly cited, appropriate credit is given, any changes made indicated, and the use is non-commercial. See: http://creativecommons.org/licenses/by-nc/4.0/.

\section{REFERENCES}

1. Berger T, Bernet V, El Alama S, et al. Perinatal care at the limit of viability between 22 and 26 completed weeks of gestation in Switzerland. Swiss Med Wkly 2011;141.

2. Tyson JE, Stoll BJ. Evidence-based ethics and the care and outcome of extremely premature infants. Clin Perinatol 2003;30:363-87.

3. Marlow N. The elephant in the delivery room. N Engl J Med 2015;372:1856-7.

4. Rysavy MA, Li L, Bell EF, et al. Between-hospital variation in treatment and outcomes in extremely preterm infants. $N$ Engl $\mathrm{J}$ Med 2015;372:1801-11.

5. Gallagher K, Martin J, Keller M, et al. European variation in decisionmaking and parental involvement during preterm birth. Arch Dis Child Fetal Neonatal Ed 2014;99:F245-9.

6. Berger TM, Steurer MA, Bucher HU, et al. Retrospective cohort study of all deaths among infants born between 22 and 27 completed weeks of gestation in Switzerland over a 3-year period. BMJ Open 2017; 7:e015179.

7. Fischer $\mathrm{N}$, Steurer MA, Adams M, et al. Survival rates of extremely preterm infants (gestational age $<26$ weeks) in Switzerland: impact of the Swiss guidelines for the care of infants born at the limit of viability. Arch Dis Child Fetal Neonatal Ed 2009;94:F407-13.

8. Berger TM, Steurer MA, Woerner A, et al. Trends and centre-tocentre variability in survival rates of very preterm infants $(<32$ weeks) over a 10-year-period in Switzerland. Arch Dis Child Fetal Neonatal Ed 2012;97:F323-8.

9. Steurer MA, Adams M, Bacchetti P, et al. Swiss medical centres vary significantly when it comes to outcomes of neonates with a very low gestational age. Acta Paediatr 2015;104:872-9.
10. Serenius F, Blennow M, Maršál K, et al. Intensity of perinatal care for extremely preterm infants: outcomes at 2.5 years. Pediatrics 2015;135:e1163-72.

11. Marlow N, Bennett C, Draper ES, et al. Perinatal outcomes for extremely preterm babies in relation to place of birth in England: the EPICure 2 study. Arch Dis Child Fetal Neonatal Ed 2014;99:F181-8.

12. Alleman BW, Bell EF, Li L, et al. Individual and center-level factors affecting mortality among extremely low birth weight infants. Pediatrics 2013;132:e175-84.

13. Kollée LA, Cuttini M, Delmas D, et al. Obstetric interventions for babies born before 28 weeks of gestation in Europe: results of the MOSAIC study. BJOG 2009;116:1481-91.

14. Schlapbach LJ, Adams M, Proietti E, et al. Outcome at two years of age in a Swiss national cohort of extremely preterm infants born between 2000 and 2008. BMC Pediatr 2012;12:198.

15. Adams M, Borradori-Tolsa C, Bickle-Graz M, et al. Follow-up assessment of high-risk newborns in Switzerland. Paedriatrica 2014;25:6-10.

16. Bayley N. Bayley Scales of Infant Development. 2nd edition. San Antonio (TX): The Psychological Corporation, 1993.

17. Bayley N. Bayley scales of infant and toddler development. 3rd ed. San Antonio (TX): Psychological Corporation, 2006.

18. Griffiths R. The Griffiths mental development scales. Association for Research in Infant and Child development. Henley-on-Thames, UK: The Test Agency, 1996.

19. Vohr BR, Stephens BE, Higgins RD, et al. Are outcomes of extremely preterm infants improving? Impact of Bayley assessment on outcomes. J Pediatr 2012;161:222-8.

20. Sharp M, DeMauro SB. Counterbalanced comparison of the bsid-ii and bayley-iii at eighteen to twenty-two months corrected age. J Dev Behav Pediatr 2017;38:322.

21. Johnson S, Moore T, Marlow N. Using the bayley-III to assess neurodevelopmental delay: which cut-off should be used? Pediatr Res 2014;75:670-4.

22. Spencer-Smith MM, Spittle AJ, Lee KJ, et al. Bayley-III cognitive and language scales in preterm children. Pediatrics 2015;135:e125 8-e1265.

23. Cirelli I, Bickle Graz M, Tolsa JF. Comparison of Griffiths-II and Bayley-II tests for the developmental assessment of high-risk infants. Infant Behav Dev 2015;41:17-25.

24. Rosenbaum $P$, Paneth $N$, Leviton $A$, et al. A report: the definition and classification of cerebral palsy April 2006. Dev Med Child Neurol Supp/ 2007;109:8-14.

25. Palisano R, Rosenbaum P, Walter $S$, et al. Development and reliability of a system to classify gross motor function in children with cerebral palsy. Dev Med Child Neurol 1997;39:214-23.

26. van BS, Groothuis-Oudshoorn K. mice: multivariate imputation by chained equations in R. J Stat Softw 2011;45 http://www.jstatsoft. org/v45/i03 [accessed 18 Dec 2015].

27. Silva LK. Validity of the risk adjustment approach to compare outcomes. Cad Saude Publica 2003;19:287-95.

28. R: a language and environment for statistical computing. Gbif.org http://www.gbif.org/resource/81287 (accessed 18 Dec 2015).

29. Adams M, Braun J, Bucher HU, et al. Comparison of three different methods for risk adjustment in neonatal medicine. BMC Pediatr 2017;17:106.

30. Leversen KT, Sommerfelt K, Elgen IB, et al. Prediction of outcome at 5 years from assessments at 2 years among extremely preterm children: a Norwegian national cohort study. Acta Paediatr 2012;101:264-70.

31. Marlow N. Is survival and neurodevelopmental impairment at 2 years of age the gold standard outcome for neonatal studies? Arch Dis Child Fetal Neonatal Ed 2015;100:F82-4.

32. Håkansson S, Farooqi A, Holmgren PA, et al. Proactive management promotes outcome in extremely preterm infants: a population-based comparison of two perinatal management strategies. Pediatrics 2004:114:58-64.

33. Smith PB, Ambalavanan N, Li L, et al. Approach to infants born at 22 to 24 weeks' gestation: relationship to outcomes of more-mature infants. Pediatrics 2012;129:e1508-16.

34. Costeloe KL, Hennessy EM, Haider S, et al. Short term outcomes after extreme preterm birth in England: comparison of two birth cohorts in 1995 and 2006 (the EPICure studies). BMJ 2012;345:e7976. 